\title{
Experiencias metodológicas ante el reto de la enseñanza de la ética
}

\author{
Rogelio Altisent Trota
}

Universidad de Zaragoza

Esta ponencia tiene como objetivo ofrecer unas reflexiones en torno a la metodología docente de la bioética, que necesariamente han de ser limitadas porque la cuestión es compleja y poliédrica.

Actualmente nadie duda de la necesidad de tomar en consideración la dimensión ética de la práctica médica y de la atención sanitaria. Es ya un tópico afirmar que la técnica por sí sola no es capaz de dar respuesta a las necesidades de la humanidad con respecto a la salud. En los foros públicos se reiteran los mensajes que hablan sobre bioética y está fuera de discusión que la ética como disciplina académica debe ocupar un lugar relevante en la formación de los profesionales. Sin embargo, no hay una correlación entre este sentimiento social e incluso corporativo y los esfuerzos que se están aplicando en la práctica.

La tesis que voy a defender es que entre el discurso académico y la realidad docente se ha abierto una brecha difícil de justificar y mantener. Me limitaré a señalar como muestra tres señales objetivas de que es necesario hacer una autocrítica en las esferas de responsabilidad de los diferentes niveles de pre-grado, postgrado y formación profesional continuada:

a) En las Facultades de Medicina españolas no se ha programado la enseñanza de la ética de manera integrada o longitudinal, y en pocas existe como asignatura obligatoria.

b) En las instituciones sanitarias se han incrementado durante los últimos 20 años las actividades formativas de ética, pero sólo asiste una minoría "ilustrada" en un curioso proceso circular y endogámico.

c) Somos bastante aburridos enseñando bioética. Aquí está, en mi opinión, la clave del retraso que tenemos en la docencia de la ética: escasea la metodología y abunda la confusión conceptual.
Algunas críticas o dudas, más o menos explícitas, que circulan actualmente sobre la bioética académica son las siguientes:

a) Por parte de los estudiantes: mucha filosofía y poca medicina

b) Por parte de los Residentes: ¿me van a lavar el cerebro?

c) Por parte de los médicos veteranos: a todo lo anterior añaden que las teorías sirven de poco, porque la ética la lleva cada uno dentro.

Intentaré exponer con brevedad algunos esquemas metodológicos que en nuestro grupo de la Universidad de Zaragoza hemos podido experimentar en estos últimos años, movidos por la preocupación de estrechar el desfase entre la teoría y la práctica, y por hacer de la ética aplicada una materia enmarcada en la mejor tradición humanista, capaz de motivar hacia la excelencia en la relación médico -paciente.

\section{¿Qué debe aprender el alumno?}

Más allá del estudio de cuestiones característica de los programas de bioética, ya sean de ámbito general ya sean las propias de las diferentes especialidades, es importante dejar claros los siguientes conceptos:

a) La evidencia científica no basta, por sí sola, para prestar una buena atención sanitaria.

b) Hay que desarrollar sensibilidad para detectar la dimensión ética de la práctica médica y abrir los ojos a la dimensión ética. Nos encontramos con diferentes tipos de cuestiones éticas que se deben diferenciar porque van a exigir diferentes soluciones: actitudes (pe. respeto al paciente); dilemas (pe. ¿damos la información ante un diagnóstico de enfermedad incurable?); el "know how": saber hacer (pe. hay que aprender a dar malas noticias). 
c) Ética y Derecho tienen mucho en común, pero son dos lógicas que es imprescindible diferenciar para prevenir la medicina defensiva. La legislación es necesaria pero no suficiente para hacer buena medicina.

\section{¿Dónde se puede aprender?}

a) Actividades de formación que ya son tradicionales: talleres, análisis de casos, seminarios.

b) En la consulta: el currículum oculto

c) Métodos de auto-evaluación: "Portafolio"

\section{¿Quién lo puede enseñar?}

a) El tutor debe jugar un papel decisivo, sin necesidad de ser un experto en bioética: enseñando a pensar, formando autodidactas capaces de establecer procesos de deliberación.

b) El propio equipo y el mismo centro sanitario: introducir la dimensión ética en las sesiones clínicas, promover la cultura institucional una ética corporativa.

c) En un nivel avanzado con profesorado especializado: títulos de postgrado, proyectos de investigación, tesis doctorales, etc.

\section{Metodología docente}

Siempre será necesario impartir algunas clases o impartir determinados temas mediante el procedimiento expositivo clásico, sin embargo, en el área de la ética aplicada se hace necesario realizar sesiones docentes que incorporen:

a) Reflexión y discusión ante casos simulados o reales: importancia de los medios audiovisuales (escenificaciones, cine).

b) Debates con expertos en oratoria: una discusión ordenada permite madurar argumentos para fundamentar la toma de decisiones.

c) Análisis de problemas éticos (pe. comparar el modo de afrontar un caso al inicio y al final de la asignatura).

\section{Metodología de evaluación}

La evaluación es una cuestión crítica, porque lo que no se puede evaluar no puede aspirar a un estatus académico. Esto se añade a la dificultad de lograr hacer de la ética clínica una materia atractiva, para lo cual hay que conjugar la exigencia con la amenidad en un área de conocimiento que pertenece al ámbito de las ciencias humanísticas, fuera de los esquemas tradicionales de la ciencia experimental. Se trata, como diría Karl Popper, de manejar unas realidades que se escapan entre las redes del método científico experimental, pero no porque no existan estas realidades, sino por la propia limitación de la red que estamos utilizando como instrumento.

Tenemos experiencia en calificar la adquisición de conocimientos, pero no es nada sencillo evaluar actitudes o habilidades en el afrontamiento de problemas éticos. Con estudiantes de pre-grado estamos ensayando con buenos resultados el siguiente procedimiento:

a) Elaboración de una memoria de la asignatura, con un cometario crítico de cada clase. No se trata de recoger los apuntes de la sesión docente (clase, discusión de un caso, debate, etc.) sino de plasmar una reflexión breve sobre su contenido, de unas 30 líneas. Se evalúa la capacidad de análisis crítico y sirve para reflejar indirectamente las actitudes, el interés, la capacidad de reflexión. La Memoria supone el $50 \%$ de la calificación final.

b) Examen tipo test (el otro 50\%) donde se permite llevar y consultar apuntes, textos, normativas, etc. Incluye preguntas sobre conceptos y casos que a lo largo de la asignatura se han señalado como conocimientos básicos.

Con médicos residentes estamos empezando a utilizar el "portafolio" como método prospectivo de autoaprendizaje y evaluación durante el periodo de especialización del médico de familia, que también se aplica a la bioética, pero pensamos que incluso será de gran utilidad para el estudiante de pregrado, en el momento en que logremos desarrollar una área de conocimiento integrada o longitudinal, de acuerdo con las nuevas directivas europeas.

Nos encontramos, sin duda, ante un reto fascinante, cuya proyección puede llegar a tener un gran impacto en el futuro de las profesiones sanitarias y en su vocación de servicio a la sociedad. Esto es algo que ya hemos podido percibir en la motivación y la actitud de los alumnos de pre-grado con quienes hemos tenido la oportunidad de desarrollar estas experiencias en la Universidad de Zaragoza.

1. CASO. Un Residente (tercer año de MIR) del Servicio de Medicina Interna recibe la visita de un médico veterano del hospital para preguntarle por el diagnóstico de una paciente ingresada en su servicio, que es amiga de su esposa y le ha pedido que se interese... a) Usted es el Residente. ¿Qué le respondería? Razone por qué actuaría así (intente explicar al menos dos razones en 15 líneas como máximo)

b) Preguntar la opinión de un médico en ejercicio y exponer por escrito en un máximo de 10 líneas (especifique su año de Licenciatura y su especialidad) 